\title{
Synergie et acides gras - XXI' siècle : une ère nouvelle pour les lipides
}

\section{Conférence présentée le 3 décembre 2004, à la $16^{\mathrm{e}}$ journée de nutrition et thérapeutique. Université Victor Segalen - Bordeaux 2}

François MENDY (Conseiller scientifique)

24, Quai du 4 Septembre, 92100 Boulogne
Abstract: The various disciplins of Science reveal a complex, consistent, and flexible world of lipids, which moreover allows for most of the biological world resilience. Marketing of Science, Commercial and Political marketing, have wanted to simplify this complex world at the most, reaching the limits of binary reduction of black and white, of Opposition and Exclusion. The Communication Mediatory Mask has ceased fulfilling its social function of interpreter, transmitter of truth. It became reducer, letting appearance to be confused with reality, disinformer by fact. Thus, the way to cognitive dissociation and repeated inconsistencies, was fully mapped out. Children of the century, researchers became heavily contaminated, and scientists were accused of inconsistancy. In the food and agri-business field, as well as in the pharmaceutical field, the sanction has been, is or will be severe (animal flours and new variants of prion disease, coxiBs or anti-Cox2). The real scientific discourse is actually very consistant, provided no acquisition, no question, neither from past nor for present time, is ignored, provided one's accepts its complexity. Several ignored questions or problems about to be solved or renewed, are raised :- Tendency to take a part for the whole, the concept of flux speed, of endogenous synthesis speed, concept of the influence of a different man made environment - Excess of exogenous or endogenous oleic acid, danger of cholesterol oleate, but requirement for a little amount of endogenous oleic acid - Phytosterols and 25-OH vitamin D- Requirement for a saturated fatty acids minimal amount. -Confusion between Vaccenic acid:-C18:1n-7trans, natural parent of Rumenic acid, and Elaidic acid (C18:1n-9trans) product of industrial hydrogenation. Furthermore new and old data on the confusion between alphalinolenic acid (in general) and alpha-linolenic in sn-2 position, the only one to be indispensable, are emerging together with the consequences of this confusion. It is logical to acknowledge Rapeseed oil as the best source of alpha-linolenic acid in sn-2 position bioavailable. It is more than questionnable for Soybean oil. The knowledge explosion last quarter of the 20 th century has made the OppositionEclusion of the P/S ratio completely obsolete. The 21 st century is opening up with three themes which are as completely different as consistent this time, Competition, Balance, Synergy. Competition can take place between five unsaturated fatty acids families: Palmitoleic, Oleic, Vaccenic $n$-7trans, Linoleic, Alpha-Linolenic, using common enzymatic systems of selective esterification, elongation, desaturation, deacylation-reacylation, and for the upper derivatives of $L A$ and ALA using numerous oxygenases. Competition can also take place intra-family, e.g. The homeostatic Thromboxane ( $n$ - 6 family) and Prostacycline ( $n-6$ family) balance in the cardiovascular field, which thus makes the exclusive interest for the phospholipids LC n-6, $n-3$ (resident drugs) somewhat insufficient. Moreover when LCn-3 inhibit COX2 which syntethise Prostacycline, Lauric acid is an inducter. The concept of Balance is fundamental, the low fat /high carbohydrate diet following, the advice of the $P / S$ « vulgate » transforming $36 \%$ of the protective A phenotype into the dangerous B phenotype (small LDLs), doubling the vascular risk. Thus the principle of precaution creates an artificial risk in $36 \%$ of the population to improve $10 \%$ of the same population! The concept of Synergy is the third theme of the 21 st century. It became indispensable with the discovery of cotranscriptionnally myristoylated proteins or peptides which play a major rôle at the phospholipidic membranes. In vitro myristic acid increases delta- 6 desaturase activity, a key step in unsaturated fatty acid métabolism. In vivo in human, the presence in the diet of myristic acid in sn-2 position, and alpha-linolenic in sn-2 position, at a precise range, is correlated with a rise of DHA in cholesterol esters and in phospholipids. Similarly LCAT activity is synergistically increased in humans by $153 \%$ by the same combination of alpha-linolenic and myristic acid both at the sn-2 position. Opposition-exclusion are the marks of the 20 th century. Competition, balance, synergy are the bases of a new era for lipids in the 21 st century.

Key words: alpha-linolenique in sn-2 position, myristique in sn-2 position, myristoylated proteins, LCAT, anti-Cox2, phenotype $A$ and $B$ 
« ...Pour innover il faut se souvenir... »

Régis Debray

Tous les systèmes biologiques disposant de régulations anticipatives savent se souvenir, pour préserver, pour innover, et c'est sans doute là le seul intérêt du souvenir. Ainsi souvenir, préservation, innovation, sont les conditions indispensables à la survie des espèces biologiques complexes confrontées à un environnement changeant [1].

II est toujours surprenant de voir le discours accompagnant la mise en évidence d'un fait expérimental, son interprétation médiatique, se limiter à une mémoire de cinq ans, évitant ainsi de rencontrer quelque " cognitive dissociation » selon l'expression de WEM Lands, ou de mettre en évidence quelques incohérences venant du passé $[1,2]$.

II devient ainsi habituel de dire que le discours scientifique n'est pas cohérent. Le scientifique ne change-t-il pas d'avis tous les cinq ans? In fine le raisonnement marketing n'est-il pas plus fiable? Ce n'est qu'au bord du gouffre que cette vulgate changera peut-être? Une perte prévue de dix milliards de dollars est-elle le bord du gouffre ? Ce sera le coût minimal d'un raisonnement marketing isolé sur un sujet situé au milieu de la lipidologie, les anticycloxygénases 2 [3].

Le moment est donc peut-être venu de montrer la cohérence du vrai discours scientifique de 1904 à 2004, et, si l'on prend conscience de cette continuité, de découvrir de nouveaux horizons, aboutissements logiques, cohérents, de cette longue histoire. En un siècle (19042004), I'acquisition de connaissances nouvelles en matière de lipides s'est poursuivie de façon continue, cohérente, en plusieurs étapes. Mais, il existe en fait de nombreux chevauchements entre ces étapes, et il est fréquent qu'entre le début de l'introduction d'une nouvelle question et l'acceptation de la solution définitive apportée, un demi-siècle se passe.

\section{4-1982 : identification des nutriments indispensables}

Cette première étape est celle de l'identification des nutriments indispensables, c'est-à-dire non synthétisables par l'organisme et jouant un rôle essentiel : I'acide linoléique (LA) et l'acide alpha-linolénique (ALA).

Ils sont aussi appelés acides gras parents (figure 1) car de chacun d'eux dérivent cing acides gras jouant également, de façon plus ou moins importante, des rôles essentiels. Très tôt, les régulations complexes de la synthèse de ces dérivés sont soupçonnées. Elles ne sont pas encore toutes parfaitement élucidées. Et très vite naquit la tentation d'attribuer la primauté des effets, selon son sujet préféré d'étude, à I'un des dérivés, au détriment des autres, et en particulier de l'acide gras parent, ceci au mépris de toute conception du rôle homéostasique de ces régulations.

L'avertissement de René Thom, dès 1984, « la science ne doit pas être une mutilation considérable de la vérité », est souvent singulièrement oublié.

En fait, ces deux acides gras polyinsaturés, LA et ALA, sont la clé de voûte d'un système compre- nant pour chacun, cinq acides gras hautement insaturés, et au moins 27 dérivés oxygénés complexes physiologiques.

Dans certains cas, lorsque la vitesse de synthèse de ces dérivés ou d'autres acides gras devient insuffisante en situation physiologique et/ou pathologique, soit temporairement, soit pour une plus longue durée, mais aussi en raison de l'environnement, face à des besoins accrus et/ou modifiés, peut naître "l'indispensabilité » temporaire d'acides gras non habituellement indispensables (encadré 1).

॥ est aussi des cas où l'équilibre apport/ synthèse, présent depuis les débuts de la préhistoire, est rompu. Qu'il fût végétarien ou carnivore, I'Homme ingérait des structures phospholipidiques, aussi riches en AGPI, ou AGHI, qu'en acides gras saturés. Ainsi un équilibre apport/synthése était toujours possible, sur le plan des saturés. L'apport n'était jamais si bas que la synthèse ne put le compenser sauf en période de famine. II a fallu la deuxième partie du XX' siècle pour que l'on s'aperçoive, avec difficultés, qu'au moins sur le plan expérimental cet équilibre pouvait être rompu. Depuis le premier travail de Hopkins CY en 1955, il a fallu plusieurs travaux (Kramer JKG...), avant que Joyce Beare-Rogers envoie une « lettre de repentance » à Nutrition Reviews (1995, 53 (9) : 269) : «Are Saturated Fatty Acids Essential in the Diet?... While low and negligible levels of saturated fatty acids may excite advertisers of food fats, some caution should be exercised. Is the old adage about moderation in nutrition matters no longer applicable to saturated fatty acids? »

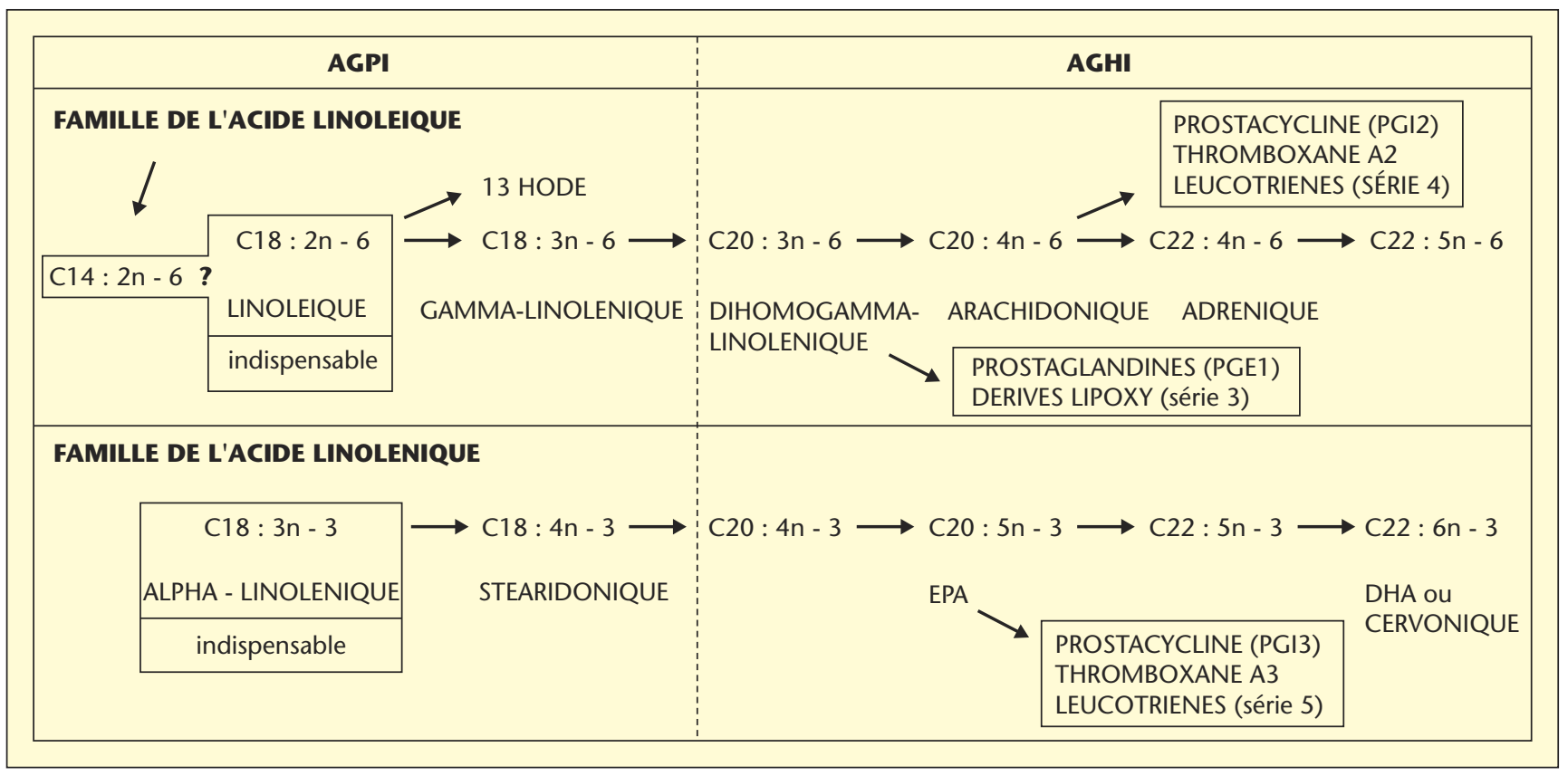

Figure 1. Les douze acides gras essentiels : AGPI (acides gras polyinsaturés), AGHI (acides gras hautement insaturés). 


\section{Encadré 1}

- Temporairement : c'est ainsi que dans la phase néonatale l'oléique exogène peut devenir indispensable, la vitesse de synthèse est insuffisante face aux besoins [4]. II faut noter aussi que l'oléique exogène en excès peut avoir par lui-même un rôle négatif ou délétère [5], de même d'ailleurs que I'oléique endogène s'il est synthétisé en trop grande quantité (hyperinsulinisme, diabète de type 2). Enfin, un apport trop élevé $d^{\prime}$ acide oléique exogène est capable d'inhiber la synthèse du minimum d'oléique endogène indispensable ayant seul accès à un chemin préférentiel [6], et peut, de ce fait, créer une situation pathologique. L'acide oléique $n^{\prime}$ 'st en rien neutre.

- Pour une longue durée. Exemple: en raison de l'environnement, I'Homme sait synthétiser le 7-dehydrocholesterol, présent au niveau de sa peau, mais seule l'irradiation solaire lui permet de synthétiser à partir de ce 7-dehydrocholestérol la vitamine D3 ou cholécalciférol. Une hydroxylation en 25 au niveau du foie, puis en 1 au niveau du rein amènera ensuite à la forme active de vitamine $\mathrm{D}$ [8].

Or, les phytostérols inhibent I'hydroxylation hépatique en $25(p<0.001)$, chez I'Homme [7]. Ainsi l'irradiation solaire, l'apport en (pro)vitamine D3, peuvent ne plus être suffisants, et c'est le $25 \mathrm{OH}$ cholécalciferol qui devient indispensable.

L'identification des nutriments indispensables se termine-t-elle en 1982 avec la démonstration de l'indispensabilité de l'acide alphalinolénique [9]?

Certes, l'Homme est toujours en mesure de faire naître des anomalies environnementales capables de bloquer et/ou de rendre peu efficaces, par exemple, les synthèses des dérivés du linoléique ou de l'alphalinolénique, de la vitamine D3..., les rendants ainsi ipso facto épisodiquement ou conditionnellement indispensables, mais d'autres nutriments indispensables sont-ils apparus?

Deux exemples très différents semblent devoir être retenus :

- L'acide vaccénique C18:1n-7 trans [10]. C'est l'acide gras parent du ruménique, C18:2,9cis, n-7trans, ou C18:2,9cis, 11 trans, présent dans le lait maternel. Tous les laits de mammifères contiennent d'ailleurs ces deux acides gras. On ne sait pas si l'Homme est capable de synthétiser le vaccénique n-7trans, mais à partir de ce vaccénique $n-7$ trans, il peut par une désaturation en delta 9 synthétiser le ruménique. L'avenir dira si l'acide vaccénique est conditionnellement indispensable, ou même indispensable.
- L'obligation de la position en sn-2 pour l'acide alphalinolenique sous peine d'inefficacité. Le problème de la biodisponibilité est dans certains cas aussi important en nutrition que dans l'industrie du médicament. L'article princeps de Holman RT en 1982 [9] établit définitivement l'indispensabilité et l'essentialité de l'acide alphalinolénique. Peu de gens remarquèrent que l'acide alphalinolénique avait été donné par voie intraveineuse, dans un système insulinosécréteur, bloquant toute « suppléance endogène » [11] ou toute « redistribution systémique » [12]. Le problème de la biodisponibilité était ainsi parfaitement contourné, et les meilleures conditions pour la mise en valeur d'un effet indispensable et essentiel, réunies.

Ainsi, donné par voie intraveineuse, l'acide alphalinolénique guérit toutes les anomalies neurologiques du syndrome de carence présent, et le valide de ce fait comme syndrome de carence en $n-3$. On peut donc affirmer que la synthèse des dérivés hautement insaturés à longue ou très longue chaîne en n-3, ou $\omega 3$, EPA et DHA, a été parfaitement réalisée dans ce cas.

C'est ainsi que Holman fixa le besoin en ALA, à $0,54 \%$ de l'énergie totale par voie intraveineuse. II s'ensuivit un rapport LA par voie orale $5,4 \%$ ET/ALA par IV 0,54 \% ET = 10/1 pour le moins étrange sur le plan physiologique.

Le problème de la biodisponibilité per os de I'acide alphalinolénique était totalement occulté. C'est en fait l'acide alphalinolénique en sn-2 qui est indispensable per os, comme une série d'études le montrera.

En 1968, nous avions proposé [11], sur des bases physiologiques, chez le nourrisson, comme besoin en LA par voie orale 5,5\% ET, au-delà la transformation en arachidonique se faisait mal. Ce taux fut contesté par Holman, puis après la publication d'un travail de $R$. Olegard en 1971 [13] qui proposait 5,4 \% ET, validé à 5,4 \% ET par Holman en 1973 [14].

Deux travaux successifs, réalisés en France, avec de l'huile de colza, vont permettre d'aboutir à un rapport LA par voie orale/ALA par voie orale plus cohérent. $M$. Lasserre et al. en 1985 [15] proposent un rapport $L A / A L A=6 / 1$, à la suite d'un travail chez des sujets adultes sains (moines). $S$. Renaud et al. en 1994 [16] proposent un rapport de 4,5/1, chez l'adulte soit $L A=7,7 \mathrm{~g}$ par $\mathrm{j} / \mathrm{ALA}=1,71 \mathrm{~g}$, à la suite d'un travail de prévention secondaire (Lyon Diet Heart Study). II semble que I'on $s^{\prime}$ oriente de plus en plus vers un rapport $5 / 1$ à $6 / 1$, en raison d'interactions entre le récepteur LDL et les VLDL naissantes sur le chemin sécrétoire résultant en un ciblage de l'apoB vers une dégradation présécrétoire [17].

Entre-temps, après des travaux de l'école de Desnuelle, dès les années 60-70, sur l'intérêt de la position en sn-2, P. Clouet, J. Bézard et al.
[18] en 1989 montraient une très rapide et sélective bêta-oxydation mitochondriale de I'acide alphalinolénique libre. II existe ainsi une « vulnérabilité » considérable de l'ALA libre ou facilement libérable. Seul I'ALA en sn-2 sur le triglycéride alimentaire, non libérable par la lipase pancréatique, est protégé de cette bêtaoxydation mitochondriale préférentielle. Dès l'absorption intestinale sous forme de monoglycéride en sn-2, il rentre ainsi dans un chemin préférentiel, directly channeled, vers I'EPA et le DHA, via sa position en sn-2 conservée au niveau des phospholipides.

Mais aussi grâce à une affinité privilégiée pour la LCAT (lécithine-cholestérol-acyl-transférase) [19] particulièrement à cette position en sn-2, il apparaît au niveau des esters de cholestérol, fournissant ainsi la meilleure signature de sa biodisponibilité [22].

Dès lors, une comparaison, sur le plan de la biodisponibilité de l'acide alphalinolénique, des huiles qui en contiennent, devenait souhaitable (encadré 2).

Une série de travaux chez l'homme sont apparus avec l'utilisation d'acides gras deutérés, validant ces données, mais aussi montrant qu'in vivo, dans certaines conditions, un mécanisme d'isomérisation pouvait permettre une migration de la position sn-1,3 à la position sn-2 du $2 \mathrm{H}-18: 2 \mathrm{n}-6$, à la condition dans l'exemple étudié que le $2 \mathrm{H}-16: 0$ migre de la position sn-2, en sn-1,3. Toutefois, ce mécanisme n'est que partiellement efficace, et le $2 \mathrm{H}-16: 0$ en position sn- 2 inhibe la synthèse de $2 \mathrm{H}-20: 4 \mathrm{n}-6$ au niveau des PC chez les quatre sujets d'âge moyen étudiés [21] d'au moins un tiers. Il est probable qu'il en sera de même pour le stéarique en sn-2. Et de toute façon, la situation est encore plus mauvaise pour I'ALA.

Comme très souvent depuis quelques années, certains auteurs oublient de préciser l'origine de l'acide alphalinolénique qu'ils étudient (oubli peu admissible dans le domaine de la santé publique), il est toujours possible de corriger cet oubli, en comparant le taux d'ALA obtenu dans les esters de cholestérol circulant et l'apport en ALA alimentaire. Normalement une corrélation très significative doit être retrouvée, tant avec les apports qu'avec les effets biologiques [22] permettant d'évaluer l'apport en ALA biodisponible réellement amené.

\section{6-1989}

C'est la deuxième étape celle de l'opposition $\mathrm{P} / \mathrm{S}$, le temps de l'opposition-exclusion.

Elle fut dominée par l'école d'épidémiologie d'Ancel Keys, F. Grande, et la Seven Countries Study.

Depuis la Minnesota Coronary Study (19751989), I'Étude australienne (1978), l'Étude 


\begin{tabular}{|lcc|}
\hline \multicolumn{2}{|c}{$\begin{array}{c}\text { Encadré } 2 \\
\text { Position en sn-2. }\end{array}$} & Huiles et biodisponibilité de l'alphalinolénique \\
& & \\
Soja & LA & ALA \\
Colza & $43 \%$ & $27 \%$ \\
& $60 \%$ & $60 \%$
\end{tabular}

Pour obtenir 0,54 \% ET d'ALA intraveineux, il faut donc $0,54: 60 \times 100=0,9 \%$ ET d'ALA per os avec I'huile de colza. $(5,4 \%$ de LA-Colza correspond à $(5,4: 100 \times 0,6) 3,24 \%$ de LA biodisponible). Le besoin en LA per os étant établi à $5,4 \%$ de LA-Colza per os pour nous, le rapport 5,4\% LA per os $/ 0,9 \%$ ALA per os de $6 / 1$ reste le plus solide et le plus pragmatique (ou 3,24 LA biodisponibl/0,54 ALA biodisponible $=6 / 1$ )

Pour un apport de 2000 calories ceci donne :

$\mathrm{LA}=5,4 \% \mathrm{ET}=$ autour de $12 \mathrm{~g} / \mathrm{j} ; \mathrm{ALA}=0,9 \% \mathrm{ET}=$ autour de $2 \mathrm{~g} / \mathrm{j} ;$ Total AGPI $=14 \mathrm{~g} / \mathrm{j}$. Soit $6,3 \%$ de l'ET et d'une façon plus pragmatique $20 \mathrm{~g}$ d'huile de colza $+10 \mathrm{~g}$ d'huile de tournesol/jour (le rapport LA/ALA au niveau de I'huile de colza étant de 2,25/1, une huile riche en $L A$, dépourvue d'ALA, s'avère nécessaire en complément. (La facilité de l'estérification du linoléique en sn-2 durant la synthèse de novo des triglycerides, sa relative protection de ce fait de la bêta-oxydation mitochondriale, son homéostasie favorable entre estérification et oxydation, rend ainsi moins stricte la notion de biodisponibilité pour LA).

Les apports nécessaires de ces deux acides gras, pour un même résultat biologique, seront très différents avec le soja, seule autre source de ALA d'usage habituel en France.

Pour obtenir 0,54 \% ET d'ALA intraveineux, il faut avec le soja 0,54:27 × $100=2 \%$ ET d'ALA per os $(4 \mathrm{~g}, 4 / \mathrm{j})$.

Avec une biodisponibilité LA équivalente à celle du colza $(5,4 \%: 43 \times 60=7,53 \% \mathrm{ET})$, un rapport LA per os/ALA per os $=7,53 \% \mathrm{ET} / 2 \% \mathrm{ET}=3,8 / 1$ s'avère nécessaire dans la meilleure hypothèse, en fait irréaliste et irréalisable.

En effet pour un apport de 2000 calories ceci donnerait, en théorie : LA = 7,53\% ET = autour de $16 \mathrm{~g}, 7 / \mathrm{j} ; \mathrm{ALA}=2 \%$ ET = autour de $4 \mathrm{~g}, 4 / \mathrm{j} ;$ Total AGPI $=21 \mathrm{~g} / \mathrm{j}$

L'apport en AGPI passerait ainsi de $14 \mathrm{~g} / \mathrm{j}(6,3 \% \mathrm{ET})$ avec le colza, à $21 \mathrm{~g} / \mathrm{j}(9,5 \% \mathrm{ET})$ avec le « soja idéal ", conduisant à un excédent de $7 \mathrm{~g}$ par jour d'AGPI éminemment peroxydables.

Mais le rapport LA/ALA dans I'huile de soja courante est de 7/1. Les apports LA/ALA doivent être alors calculés séparément. Une série de déséquilibres potentiels apparaissent alors : par exemple $10 \%$ de l'ET sous forme d'AGPI provenant de l'huile de soja amènent pour 2000 calories, 22,2 $\mathrm{g}$ d'AGPI, $19 \mathrm{~g} 4 \mathrm{de}$ LA (dont 8,35 g biodisponible) et au maximum 2,8 $\mathrm{g}$ d'ALA, (: $100 \times 27$ ), soit $0 \mathrm{~g} 75$ de biodisponible ou $0,34 \% \mathrm{ET}$, assurant seulement $63 \%$ des besoins en ALA, et ceci au prix d'une surcharge en acides gras polyinsaturés très oxydable de $8 \mathrm{~g} / \mathrm{j}$.

Si I'on veut obtenir $100 \%$ des besoins en ALA, il faut donner $10 \%: 63 \times 100=15,8 \%$ de l'ET d'AGPI sous forme d'huile de soja (soit $30 \mathrm{~g}$ de LA, $4,4 \mathrm{~g}$ de ALA), et de façon pragmatique 60 $\mathrm{g}$ d'huile de soja/jour avec un rapport de LA biodisponible/ALA biodisponible $(8,33 \mathrm{~g} / 0,75$ g) $=11,1$

Ce rapport de LA/ALA de $10 \%$, ces taux d'AGPI à $16 \%$ ET, d'apport de $80 \mathrm{~g} / \mathrm{j}$ d'huile de soja, sont rencontrés dans la littérature américaine favorable aux AGPI ou PUFA.

Mais « the percent conversion of $18: 3 n-3$ was reduced by $40 \%-54 \%$ when the amount of dietary $18: 2 \mathrm{n}-6$ was increased from $15 \mathrm{gr} /$ day to $30 \mathrm{gr} /$ day » (Emken [20]).

L'huile de soja donnée à dose suffisante crée de mauvaises conditions de transformation de I'ALA en dérivés supérieurs EPA et DHA, mais aussi du LA en arachidonique (dès $5,5 \%$ de l'ET $[11,20]$ (figure 6).

Ainsi le consommateur d'huile de colza peut se passer d'huile de poisson, mais le consommateur d'huile de soja ne le peut pas, à moins d'une consommation élevée en chair de poisson et d'alicaments.

d'Oslo, (1986-1987), la Lyon Heart Study (1987-1994) (figure 6), elle était difficilement soutenable. FB Hu [23] vient de définir en quelques mots l'opinion qui se généralise de plus en plus : « ... in the past too much has been made of ecologic associations between saturated fat and CHD derived from the Seven Countries Study. »
Un étonnant article de PM Kris-Etherton, financé par Frito-Lay Inc. Plano Texas « Polyunsaturated Fatty Acids and Cardiovascular Health " vient de paraître dans Nutrition Reviews en novembre 2004 [24]. II regroupe tous les arguments en faveur des «PUFA » sans dissocier LA et ALA ainsi que les 75 références majeures parues depuis 1956. Le point de vue est essentiellement celui de l'épidémiologiste, celui du physiologiste et du biochimiste est rejeté.

Mais il est difficile de rejeter les études cliniques prospectives, n'ayant pris comme seul critère que les «High PUFA ». Pour contrebalancer l'effet négatif de la Minnesota Coronary Study (4 393 hommes, 4664 femmes), l'auteur ajoute quatre autres études : Los Angeles Veteran $(n=422)$, la $1^{\text {ère }}$ Oslo Diet-Heart $(n=412)$, Finnish Mental Hospital $(n=393)$, British Medical Reserarch Council $(n=393)$ soit 2327 sujets, et conclut : « Collectively, these diet studies have shown (...) $25-43 \%$ reduction in cardiovascular events. (...) Moreover although not every study reported significant positive outcomes, the higher intakes of PUFA dit not result in worsend morbidity or mortality!!! » (figure 6).

Le lot expérimental de l'étude British Medical Research Council [25] consommait $85 \mathrm{~g}$ d'huile de soja. La Lyon Diet Heart Study n'est pas citée, ni la révision de l'étude d'Oslo. L'auteur reconnaît pourtant «In contrast, PUFAs tend to be positively associated with measures of oxydative stress due to their high degree of unsaturation ».

D'autres éléments factuels ressortent de cet article :

- Sur le plan de la consommation, une nette évolution aux États-Unis :

- NHANES I (1972), LA = 4,3 \% ET (ANC 2003 en France $=4 \%$, pour une consommation probable en moyenne (Suvimax) de 4,13\%);

- NHANES II (1978), LA = 5,7 \% ET ;

- NHANES III (1991) LA $=7,1 \%$ ET ; (1994) LA =6,9\% ET.

La zone médiane d'apport en AGPI va de 5,4\% $\mathrm{ET}$ à 7,3\% ET, mais certaines femmes entre 40 et 49 ans atteignent $22 \%$ de l'ET sous forme de PUFA ! Comme, durant cette période, les deux huiles végétales consommées aux ÉtatsUnis étaient I'huile de soja et l'huile de maïs, certains consommateurs devaient frôler les besoins minimaux en ALA, mais dans des conditions de transformation de ALA en dérivés supérieurs médiocres. Enfin, cette évolution est parallèle à une chute de la consommation en lipides, une augmentation de la consommation en glucides (régimes Low-Fat, HighCarbohydrates). On note également sur le plan épidémiologique, dans le même temps, l'augmentation de l'obésité, du syndrome métabolique, du diabète de type 2 , etc.

- Sur le plan recommandation, de grandes différences apparaissent selon les pays:

- États-Unis : «n-6 PUFA » : 5 \%-10 \% ET avec $17 \mathrm{~g}$ de LA/j pour les hommes, $12 \mathrm{~g} / \mathrm{j}$ pour les femmes ;

- Commission européenne : $4 \%-8 \%$ de l'ET pour les «n-6 PUFA »;

- OMS : 5-8 \% pour les «n-6 PUFA»; 


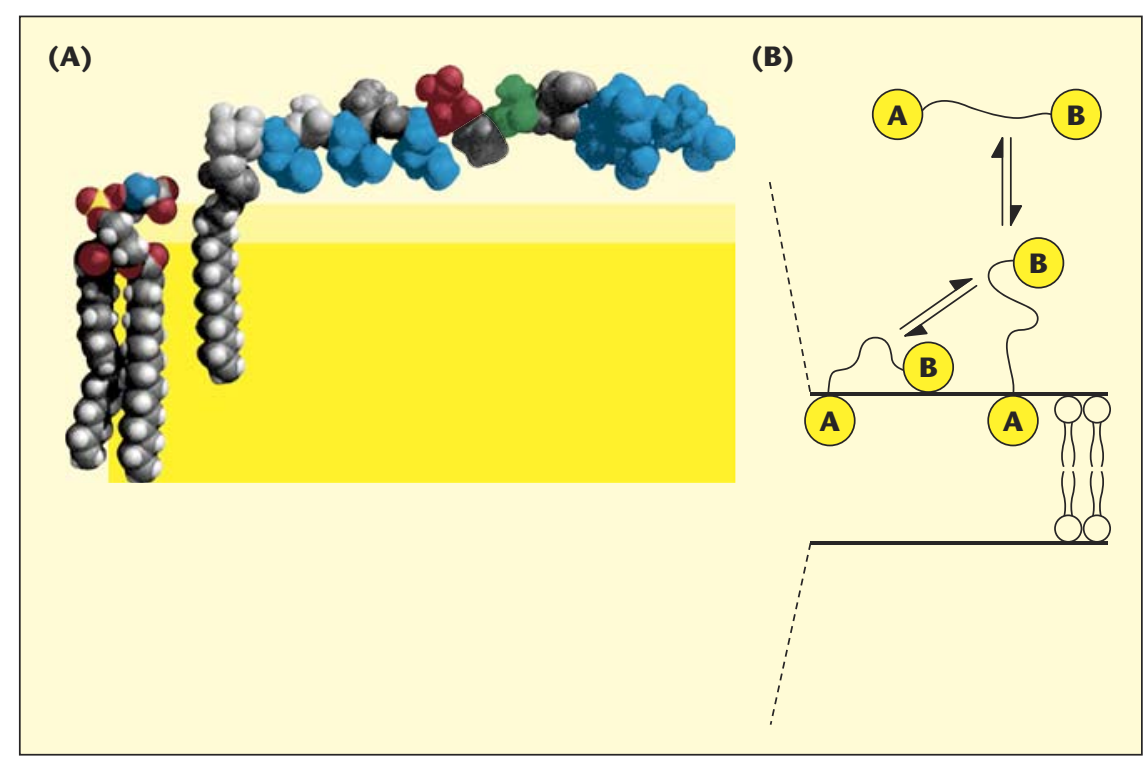

Figure 2. A) Modèle moléculaire de l'interaction de la région amino-terminale de la protéine SRC avec une membrane bicouche. SRC contient quatre domaines importants : le domaine amino-terminal se liant à la membrane et illustré dans cette figure, les domaines homologues de SRC SH3 et SH2, qui médient les interactions protéines-protéines, et un domaine sensible à la tyrosine kinase (pouvant être phosphorylé-déphosphorylé). Les expérimentations avec les peptides SRC myristoylés suggèrent que dix groupes $\mathrm{CH} 2$ de la chaîne acyle pénètrent à l'intérieur de la membrane et quatre $\mathrm{CH} 2$ traversent la région des têtes polaires. Le myristate 15 résidus peptide (myristate-CSSKSKPKDPSQRRR) est montré dans une configuration (confirmée par des mesures physiques de dichroisme circulaire) parallèle mais approximativement distante de la surface des têtes polaires de la membrane de 1-2 molécules d'eau. Les six résidus basiques sont colorés en bleu, les résidus acides en rouge, et la sérine phosphorylable par la protéine kinase C en vert. Les résidus basiques interagissent de façon électrostatique avec les têtes acides lipidiques de la membrane comme la phosphatidylsérine (à gauche). B) Ce simple modèle illustre la coopération rendue possible par la liaison de la chaîne myristate avec les résidus basiques. Le domaine de liaison membranaire de SRC est représenté par deux sites, $A$ (chaine acyle) et $B$ (résidus basiques), relié par un «cordon» flexible, de longueur $r$. Quand A pénètre dans la membrane, B est confinée dans une hémisphère de rayon $r$, qui augmente grandement la possibilité que ce domaine basique rentre en contact et se lie de façon électrostatique avec les têtes acides phospholipidiques. Ainsi les interactions hydrophobiques et électrostatiques agissent ensemble pour ancrer la protéine à la membrane. Pour la protéine MARCKS (myristoylated alanine-rich C kinase), la phosphorylation de la sérine réduit ensuite l'attraction électrostatique et déclenche la séparation, et la translocation, "électrostatique switch ». (D'après [51]).

- Japan Society for Lipid Nutrition : LA : 3-4 \% ET :

- International Society for the Study of Fatty Acids and Lipids : LA : $2 \%$ ET, et une « Upper Limit » à $3 \%$ de l'ET. Cette position est en fait une réaction violente contre les régimes (aux États-Unis) à teneur élevée en LA et faible en $A L A$, avec le souhait de réduire les excès d'arachidonique et d'eicosanoïdes en n-6 (en fait on sait depuis 30 ans qu'à taux élevé de LA $(>6 \%)$ la synthèse d'arachidonique est « down-régulée ») [11, 21].

Après ce long plaidoyer pour les «PUFA », la conclusion est modeste. L'auteur fait remarquer que le « healthy ratio LA/ALA of $4 / 1$ » peut être rencontré avec des taux de saturés, de trans, de cholestérol excédant les taux recommandés! Elle demande : « to focus on recommended levels rather than the ratio. » Enfin : " Research is also needed to determine the amount of linoleic acid in the diet necessary to achieve maximal benefits on certain end points such as lipids and lipoproteins, but still remain at a level that does not result in detrimental effects on emerging risk factors such as oxidative stress and adhesion molecules. »

On ne peut que pleinement souscrire à la dernière phrase de cet article. "baroud d'honneur" le P/S est devenu insaturés/saturés (mais aussi insaturés se divisent en oléique + linoléique + alphalinolénique, dans un rapport pour nous de l'ordre de 12-13/6/1).

À titre d'exemple, dans le groupe d'étude (colza) de la Lyon Diet Heart Study, les apports étaient les suivants :

- oléique $=12,9 \% \quad E T$, soit $26,4 \quad \mathrm{~g} / \mathrm{j}$, $\mathrm{LA}=3,6 \% \mathrm{ET}$, soit $7,7 \mathrm{~g} / \mathrm{j}, \mathrm{ALA}: 0,81 \% \mathrm{ET}$, soit $1,75 \mathrm{~g} / \mathrm{j}$.

- $\mathrm{P} / \mathrm{S}=0,69, \quad \mathrm{LA} / \mathrm{ALA}=4,5 / 1, \quad$ Cholesté$\mathrm{rol}=217 \mathrm{mg} / \mathrm{j}$ (soit OL/LA/ALA = 15,9/4,4/1). Cette diète méditerranéenne n'atteint en rien les 45-50 g d'oléique préconisés par ailleurs (20\% ET) (ANC 2003) et qu'aucune population méditerranéenne n'a jamais atteint, au moins sur une longue durée. Si au cours de cette deuxième étape le $\mathrm{P}$ du rapport $\mathrm{P} / \mathrm{S}$ a
En fait, inexorablement, malgré ce dernier explosé, à l'exception de quelques biochimistes fascinés par la découverte des acylations des séquences protéiques et/ou peptidiques, par des acides gras saturés, en co-transcriptionnels, ou en post-transcriptionnels, le $S$ était considéré comme une entité globale, monolithique. Et ce n'est qu'en 1999 que FB Hu et al. [26] publiaient la première étude épidémiologique qui analysait le rôle d'acides gras saturés spécifiques en relation avec le risque d'athérosclérose. "Long chain SFA (C12-C18). (...) a modest increased risk ». Le « Risk Ratio » multivarié le plus élevé était atteint avec le $4^{\mathrm{e}}$ quintile le plus élevé de stéarique: Multiv. $\mathrm{RR}=1,30, p=0,009$ pour un apport de $4,09 \%$ de l'ET. Le myristique présentait une courbe en $\mathrm{U}$ avec un Multiv. RR à 0,96, pour un apport de $1,45 \%$ de l'ET, $p=0,07$. Le risque ratio multivarié ne dépassait 1 qu'à partir d'un apport de $8,2 \%$ de l'ET pour le Palmitique. Cette étude, réalisée sur 80082 infirmières, est certainement la plus pertinente de celles publiées sur ce sujet, mais si l'apport en linoléique était dans le cadre d'une fourchette probablement physiologique, ce n'était certainement pas le cas de l'apport en alphalinolénique, et peut-être même de l'apport en oléique.

Ce n'est que maintenant que nous sommes devenus capables de mener des études prospectives dans le cadre de fourchettes physiologiques d'apport en oléique, linoléique, linolénique, et d'éliminer ainsi les biais introduits par des apports anormaux de l'un ou l'autre de ces acides gras insaturés comme c'était toujours la règle, dans toutes les études conduites dans cette période, sans parler de l'apport en cholestérol.

Pour des biochimistes fondamentalistes comme WEM Lands, la réputation des acides gras saturés était « un article de foi » mais « It was not clear at the time (2002) (or even today !) what the saturated fat might actually be doing to harm health » [27].

\section{0-1990 : explosion des connaissances}

L'élucidation des rôles physiologiques, fonctionnels, des dérivés oxygénés enzymatiques contrôlés, du linoléique et du linolénique entraîna une véritable explosion des connaissances. Au-delà des cinq dérivés de chacun de ces acides gras parents que sont le linoléique et I'alphalinolénique, phospholipases A2, cycloxygénases 1 et 2, lipoxygénases $5,12,15$, cytochromes P450, mono-oxygénases, vont permettre la synthèse de 20 autres dérivés physiologiques dans chaque famille sans compter les lipoxines. Derrière le nom global d'eicosanoïdes, sont ainsi regroupés les prostaglandines, thromboxanes, prostacyclines, leu- 
cotriènes... (ou n-6 hormone-like) autacoïdes (ou n-3 hormone-like, autacoïdes (d'après auto = soi, akos = guérir) (figure 3)).

Le problème majeur devenait comment régler I'homéostasie de ces quarante dérivés majeurs, nier l'existence ou l'intérêt de certains comme la prostacycline ( $\mathrm{PGI} 2$ ) ne pouvait conduire qu'à des drames.

De plus, en cas de déséquilibres divers, peuvent naître des dérivés non physiologiques d'oxydation non contrôlées : $13 \mathrm{HO}-\mathrm{DE}$, dérivé du linoléique, (base des LDLs oxydés, I'un des facteurs les plus importants de l'athérogenèse), isoprostanes $(n-6)$, isolevuglandines $(n-6, n-3)$.

Pourtant, dès 1982, dans son allocution de remise du Prix Nobel de physiologie et de médecine à $S$. Bergstrom, B. Samuelson et J. Vane, B. Pernow [28] définissait parfaitement la situation nouvelle créée: "To maintain the balance and to prevent it from being upset by external or internal stress factors, nature has provided us with a number of regulatory systems. (...) Prostaglandins and related biologically active substances constitute one of the systems. (...) Unsaturated fatty acids form the parent substance for this system. » « Biological system that plays a decisive role in normal life process but also contributes to the disbalance that characterizes several diseases. »
Simplement, personne n'envisageait à l'époque, qu'apprenti sorcier, l'Homme allait créer en voulant intervenir sur ce système, sans grande prudence, de nouvelles situations de déséquilibres inconnues jusque-là.

Mais si l'on quitte le domaine des acides gras polyinsaturés, pour le domaine des acides gras saturés, dans la même période, le domaine de la fonctionnalisation des peptides et des protéines explose. II existe ainsi plus de cent protéines myristoylées en co-transcriptionnels [29-31].

S'il existe également des acylations de protéines avec l'acide palmitique, celles-ci sont posttranscriptionnelles, via une liaison thioester (S-acylation) avec les résidus cystéine de protéines membranaires. Alors que les myristoylations co-transcriptionnelles sont des attachements co-valents de l'acide myristique, via un lien amide avec le $\mathrm{NH} 2$-terminal du résidu glycine de diverses protéines ou peptides cellulaires. On est très loin du rôle énergétique, voire structural (dans les $\mathrm{PL}$ ), des acides gras saturés. Nous abordons ici, avec le XXI ${ }^{\mathrm{e}}$ siècle, le rôle fonctionnel, des acides gras saturés : «The fats of life: the importance and fonction of protein acylation. » (RAJ Mcllhiney, 1990 [32]). Et ce myristique doit être également en sn-2 (figure 2).
(Une seule source alimentaire en sn-2 est possible, la matière grasse lactique. On ne connaitt pas les besoins, et les limites de la production endogène de myristique en sn-2.)

\section{$X X I^{\mathbf{e}}$ siècle : synthèses, équilibres, synergies}

Des temps nouveaux apparaissent: le temps des compétitions inter- et intra-familles, le temps des équilibres, le temps des synergies. Mais c'est aussi la réhabilitation des acides gras parents biodisponibles, la remise en question du tout épidémiologie. Enfin une variante grave de l'écologie apparaît avec le « No Disturb Physiology » [33].

\section{Compétitions inter- et intra-familles}

Trois exemples permettent de mieux cerner l'importance de ce problème.

\section{Le rapport LA/ALA :}

compétition entre famille $d^{\prime} A G P I$

II gère les compétitions entre deux familles d'AGPI et d'AGHI, la famille linoléique et la famille alphalinolénique, face à des systèmes enzymatiques communs d'estérification sélective (synthèse de novo Tgs et Pls, « retailoring

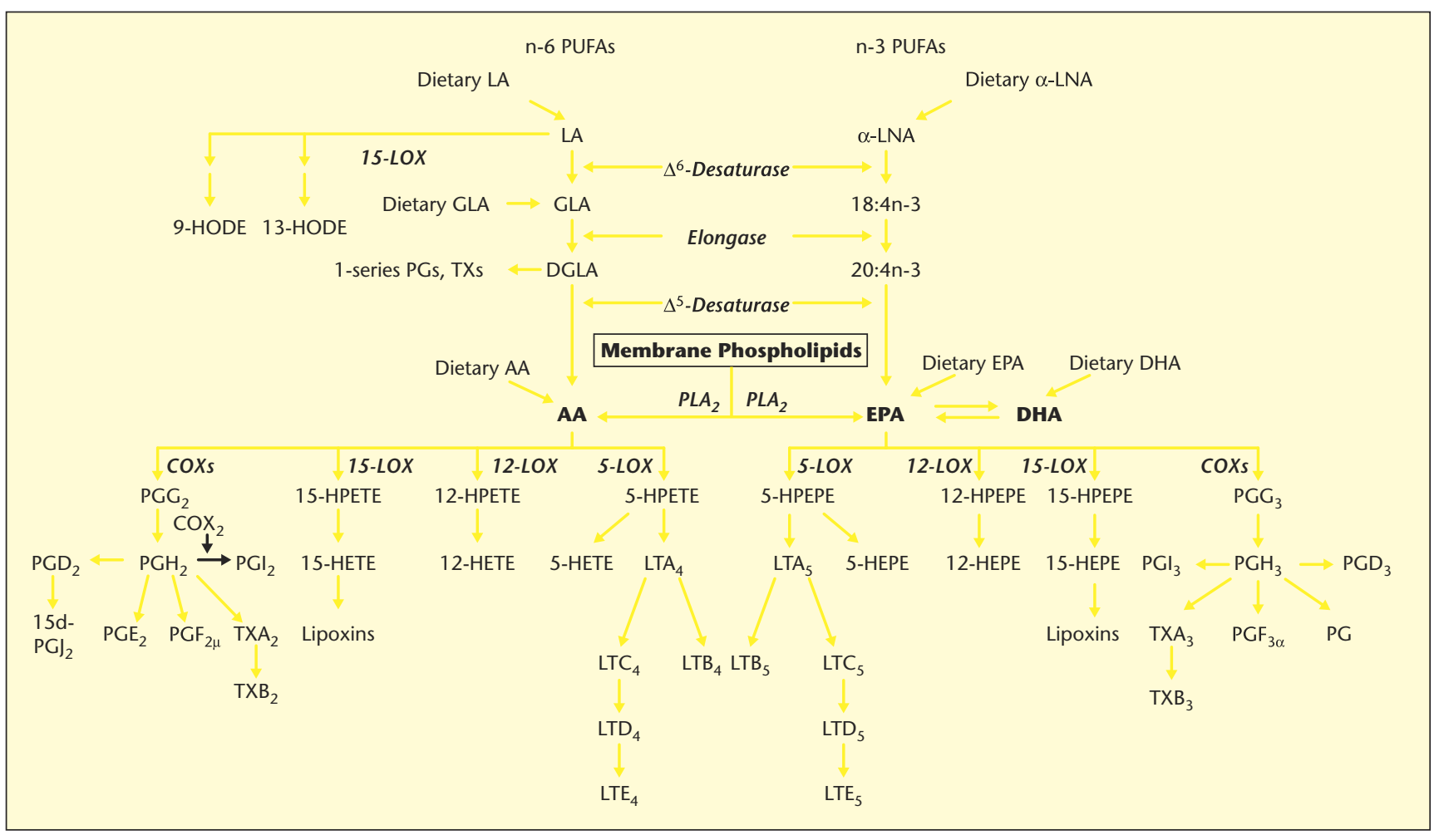

Figure 3. Les « 40-45 » dérivés physiologiques majeurs.

Les niveaux de synthèse : cibles des médicaments : 1) Contrôle général : phospholipase A2 : PLA2 et corticoïdes. 2) Contrôles ciblés de première génération. Exemple: les cyclogénases COX et anti-inflammatoires non stéroïdiens. 3) Contrôles ciblés de deuxième génération. Exemple : les cyclogénases inductibles dites COX2, les anti-cox2 ou coxibs, mais aussi AGHI n-3 (inhibiteurs), acide laurique (inducteur).LOX : lipogénase, LT : leucotriènes, HODE : dérivés d'oxydation biologique non contrôlée. 
process »), d'élongation, de désaturation, face aux phospholipases, à la LCAT (lécithine cholestérol acyl transférase), aux cycloxygénases, lipoxygénases...

Mais trois autres familles participent aussi à ces compétitions, du moins pour la part, estérification sélective - élongation - désaturation, la famille de l'oléique(n-9), du palmitoléique(n7), du vaccénique trans ( $n-7$ trans). Nous $n$ 'en parlerons pas ici.

Beaucoup reste encore à faire pour comprendre l'ensemble de ce système, en particulier dans le cadre du syndrome métabolique.

Les acides gras parents biodisponibles, par apport (ou par synthèse partielle endogène pour les non-indispensables stricts), sont la clé de voûte de ce système.

Cette "competitive hyperbolic interaction" [34] reliant les apports alimentaires en LA et en ALA aux teneurs des phospholipides tissulaires des AGHI n-6 (20:3n-6+ $20: 4 n-6+22: 4 n-$ $6+22: 5 n-6)$, AGHI n-3 (20:5n-3 + $22: 5 n-$ $3+22: 6 n-3)$, et à leur proportion respective, est physiologiquement importante. Elle peut parfaitement être définie chez le végétarien. Chez l'omnivore vrai, et le carnivore, l'apport direct en dérivés supérieurs en C20n-6, n-3, $\mathrm{C} 22 \mathrm{n}-3, \mathrm{n}-6$, vient interférer, et rend très critiquables les équations établies chez le rat ne consommant que les acides gras parents LA et ALA. De plus, comme nous I'avons montré dès 1968 [11] et comme cela a encore été récemment confirmé $[20,21]$ pour $L A$, au-delà de $6 \%$ de I'ET, la transformation de LA en ALA est considérablement réduite. En fait, cette transformation de LA et ALA en leurs dérivés supérieurs est à la fois autorégulée dans chaque famille et régulée par la compétition entre familles, comme l'a encore récemment démontré Emken [20].

Par contre, la consommation d'arachidonique (C20:4n-6), sous forme de viande ou œufs, suppléments alimentaires, d'EPA (C20:5n-3), DHA (C22:6n-3) sous forme de poisson, ou suppléments alimentaires d'huile de poisson (les « oméga-3»), entraîne l'entrée dans le monde biologique d'AGHI dont le contrôle sera nettement moins bien programmé, en particulier dans le cas des suppléments, que celui des AGHI provenant de la synthèse endogène à partir des acides gras parents. À titre d'exemple, une consommation importante de poisson (trois fois par semaine) amène difficilement $200 \mathrm{mg}$ d'EPA + DHA par jour en moyenne, nous sommes loin des $10 \mathrm{~g}$, puis $2 \mathrm{~g}$, puis $800 \mathrm{mg} /$ jour proposés. Les $450 \mathrm{mg}$ plus récemment proposés à I'ISSFAL 2004 par W Harris, sont plus près du raisonnable. Quant aux Esquimaux, ils mangent surtout des mammifères marins, avec périodiquement une consommation de plantes et de dérivés biolo- giques du permafrost (source entre autres de gamma-linolénique :C18:3n-6)!

L'enjeu de ces stratégies de modifications du rapport LA/ALA alimentaire, de supplémentations directes en AGHIn-3, ou n-6, est la modification des proportions de ces AGHI dans les phospholipides tissulaires. En effet, comme l'a montré Lands [35] dès 1973, ils constituent en tant que sources d'eicosanoïdes en $n-6$, ou en $\mathrm{n}-3$, des resident drugs, libérables par la phospholipase A2. Ainsi, à titre d'exemple, augmenter les $\mathrm{AGHI}$ en $\mathrm{n}-3$, en diminuant les $\mathrm{ACH}$ en $\mathrm{n}-6$, peut diminuer les possibilités de synthèse de thromboxane A2 (de la famille $n-6$ ), principal agent de la thrombose [36]. L'ennui, c'est que cette vision des années 73-75 devint dominante. L'importance de la prostacycline [37], prostaglandine de la famille $\mathrm{n}$-6 également, découverte plus tard, mais à effets opposés, fut négligée ainsi jusqu'en 2004, malgré un Prix Nobel (Vane, en 1982). Or de la prostacycline, hormone vasodilatatrice, dépend par exemple le débit d'oxygène cérébral. Sans elle nous serions des nains cérébraux.

\section{Le rapport thromboxane A2/prostacycline $P G I 2$ compétition intra-familiale en $n-6$}

II s'agit donc cette fois-ci de deux prostaglandines de la même famille $n-6$. Systématiquement ignorée par certains depuis quinze ans, son importance vient d'exploser au grand jour. Alors que le concept de resident drug commençait lentement à s'implanter, le concevoir comme une approche réductionniste passait pour de la provocation. C'était pourtant simplement franchir l'étape suivante.

La phospholipase A2 libère de la position sn-2 du phospholipide tissulaire, I'ACHI présent, I'arachidonique (ARA)(n-6) ou EPA (n-3). Une vision simpliste permettait d'annoncer qu'étant donné que I'EPA donne naissance à des eicosanoïdes anti-inflammatoires, l'ARA à des prostaglandines inflammatoires (et thrombosantes : thromboxane), si l'on inonde l'organisme en $\omega 3$ (n-3), ce sera essentiellement I'EPA qui sera libéré par la PL A2 commune aux deux, et nous aurons un effet antiinflammatoire, anti-thrombosant...

Une autre démarche, "moins écologique", était également possible, les corticostéroïdes inhibent la phospholipase A2, leur utilisation empêchant la libération de I'ARA et/ou de I'EPA, rendra impossible la synthèse des PG correspondantes (figure 3). Mais bloquer la phospholipase A2 est se priver des actions possibles de 40 médiateurs autacoïdes : «Biological system that plays a decisive role in normal life but also contributes to the disbalance that characterizes several diseases (...) [28].

La recherche de produits plus ciblés devint I'objectif des sociétés pharmaceutiques, elle aboutit à la mise aux points d'anti- inflammatoires non stéroïdiens (AINS), qui ne bloquaient cette fois-ci qu'une seule des quatre voies possibles après la libération de l'ARA, ou de I'EPA, par la phospholipase A2, la voie des cycloxygénases (figure 3). Le succès des AINS de première génération dura quinze ans, mais il devint évident qu'au cours des traitements au long cours pouvaient apparaître des érosions gastro-duodénales, des ulcères gastrointestinaux, des hémorragies digestives (5,8 à $7,8 \%$ de "Serious Adverse Events»). Ceci coïncida avec la découverte de l'existence de deux cycloxygénases, la cox 1 constitutive, et la cox 2 inductible.

La première génération des AINS était constituée d'anticox 1 constitutives. Une nouvelle génération apparut alors celle des anticox 2 inductibles, commercialisée en 1999. Le développement de ces anticox 2 ou coxibs était basé [38] sur l'hypothèse que les cox 2 étaient la source des PGE2 et 12 qui médiaient l'inflammation, et que les cox 1 étaient la source des mêmes prostaglandines dans l'épithélium gastrique où elles offraient une cytoprotection.

Dès 1999, GA FitzGerald [38] prévint que chez des hommes volontaires sains, les anticox 2 ou coxibs supprimaient la synthèse de prostacycline (PGI2). Or il avait été montré que la PGI 2 est le dérivé cycloxygénasique prédominant de I'endothélium, inhibant l'agrégation plaquettaire, conduisant à une vasodilatation (contrôle du débit d'oxygène), prévenant la prolifération des cellules musculaires lisses vasculaires. De plus, il avait été démontré chez les souris et les hommes que la cox 2 inductible était, en fait, la source principale de prostacycline.

Ainsi, alors que l'aspirine et les AINS traditionnels inhibent à la fois la production de thromboxane $A 2$ et de prostacycline $P G 12$, les coxibs (anticox 2) laissent intacte la production de thromboxane, et inhibent la production de prostacycline. (II n'y a pas de cox 2 dans les plaquettes sanguines.) Actuellement, pour I'un des scientifiques de la FDA, le Dr David Graham, un seul de ces coxibs serait responsable de 27000 morts ou accidents cardiaques [39]. Ce produit a été retiré du commerce par son fabricant, sur sa propre initiative. Des pertes de 10 milliards de dollars ont été avancées.

Un avertissement de J. Vane (Prix Nobel de médecine 1982 pour la découverte de la prostacycline) mérite d'être rappelé: "These results provide clear evidence that PGI 2 modulates the cardiovascular actions of TXA2 in vivo (...) they further reinforce the notion that the balance between these two eicosanoids maintains cardiovascular homeostasis » [40].

\section{Le rapport laurique en sn-2/acides gras à chaîne longue ( $n-3)$}

Équilibre entre un acide gras saturé et des ACHI en $n-3=$ maintien de la régulation homeosta- 
sique de la synthèse de la cycloxygenase 2 inductible?

Dès 2001, JL Harwood, CL Curtis, de I'université de Cardiff [41] attiraient l'attention sur la réduction dose-dépendante de l'expression du mRNA de la cycloxygénase 2 inductible obtenue avec l'EPA et le DHA sur un modèle animal d'arthrite dégénérative, chondrocytes bovins en culture stimulé par l'interleukine 1A. C'est donc par deux mécanismes, celui dit de la resident drug (diminution de la teneur en AGHIn-6 des phospholipides tissulaires), celui de la répression de la synthèse de la cox 2 inductible (indispensable pour la synthése de la prostacycline $P G I 2$ ), que les $A G H I$ en $n-3$ peuvent agir sur les dérivés eicosanoïdes en n-6. En 2003, JY Lee, DH Hwanf et al. [42] montrent que l'acide laurique potentie l'expression des cox 2 inductibles.

Ainsi une boucle de régulation homéostasique acide laurique et acides gras à longue chaîne en n-3 pourrait exister. Il est curieux de noter que le lait de femme amène dans notre expérience $7 \%$ des acides gras (3,78\%) de l'ET sous forme d'acide laurique, en même temps qu'il améne $0,5 \%$ des acides gras sous forme d'AGLC $\omega 3$. Le nouveau-né doit se défendre contre toutes les infections (réactions immunologiques, inflammatoires) d'une part, et assurer d'autre part le développement de son cerveau, grâce à une synthèse ou un apport en DHA suffisant (mais aussi, en arachidonique (ARA), adrénique n-6), combiné avec un débit d'oxygène suffisant (disponibilité en ARA, cox 2 fonctionnelle).

Fragilité plaque artérielle - AGHI en n-3- cox 2 "No disturb Physiology"

Enfin une surcharge en EPA + DHA, à taux très élevés, est connue pour fragiliser la plaque artérielle athéromateuse $[43,44]$; I'inhibition conjointe de la cox 2 inductible, d'où de la sécrétion de prostacycline, ne peut être que catastrophique, ce qui est soupçonné depuis quelques années déjà [45]. Dès 2001, on savait que le Risk Ratio était pour un coxib de 2,24, $p=0,007$. II est dangereux de détruire des équilibres physiologiques, de bloquer des régulations homéostasiques.

\section{Le temps des équilibres}

Après le temps des régimes "Low Fats ", pauvres en lipides, est venu le temps des régimes "Low Carbs ", pauvres en glucides. II est difficile de faire comprendre le danger des diététiques alternatives, tant le marketing scientifique autour de la Seven Countries Study a été puissant. L'introduction d'onces de vérité, malheureusement complexes, s'avère très difficile dans un marketing forcément réducteur. Pourtant le problème est grave. La formulation la plus subtile fut ce titre : «Choose a diet that is low in saturated fat and cholestérol, and moderate in total fat: subtile changes to a familiar message » [46].

L'innovation ne peut s'avancer que masquée [2]. L'affirmation « Low in saturated fat » est ici propitiatoire!

Mais si I'on veut réduire les acides gras polyinsaturés autour de $6 \%$ de l'ET, ce qui est supérieur aux ANC 2003 (LA: $4 \%+$ ALA : $0,8 \%=4,8 \%$ ), mais rejoint le souhait de bien des scientifiques : conserver le taux de $8 \%$ des acides gras saturés par idéologie conservatrice, tout en atteignant un apport modéré de lipides totaux de $30 \%$, un apport de $16 \%$ d'oléique s'avère nécessaire (17,2 \% pour les $A N C)$. Et si I'on veut atteindre $33 \%$ de l'ET, un apport de $19 \%$ s'avérera nécessaire $(20,2 \%$ pour les ANC).

Or l'acide oléique n'est pas neutre. On sait depuis les travaux de Blankenhorn chez I'homme dès 1990 [5] que le Risk Ratio passe de 0,3 entre $9,8 \%$ et $12,3 \%$ de l'ET, à 4,91 au-dessus de $12,3 \%$ de l'ET, particulièrement au-dessus de $16 \%$ de l'ET (overkill metabolic). Ces résultats ont d'ailleurs été largement confirmés chez le singe par LL Rudell [47] (danger de l'oléate de cholestérol en excès).

Pourtant, le danger des régimes « High Carbs » s'avère de plus en plus confirmé. Sur le plan métabolique, c'est la meilleure source de surcharge en palmitique endogène, oléique endogène, entraînant une hausse du taux de sécrétion des VLDL, du rapport cholestérol totalcholestérol $\mathrm{HDL} /$ cholestérol $\mathrm{HDL} \quad(=\mathrm{CVLDL}+$ $\mathrm{CIDL}+\mathrm{CLDL} / \mathrm{CHDL}$ )/cholestérol HDL, particules Apo B/Apo A1, des "small Ldls ", et d'une façon plus générale de la prévalence du syndrome métabolique dont l'importance grandit chaque année (mal mis en évidence par le simple rapport $\mathrm{CLDL} / \mathrm{CHDL}$ ).

L'étude de la variation de taille des particules LDL a conduit à la mise en évidence de deux phénotypes [48] :

- phénotype $B$ : particules $L D L$, plus petites, plus denses, plus oxydables, "small LDLs », qui se sont révélés associés avec des taux de triglycerides élevés, et un risque de maladies coronariennes multiplié par trois versus;

- phénotype A: "Buoyant» particules LDL moins oxydables, TG bas, HDL élevés.

Les sujets qui expriment le phénotype $B$ avec une consommation élevée de matières grasses, réagissent bien au régime "Low Fats » (étape 2 du régime de l'AHA): baisse des $L D L$ et de I'Apo B, suggérant une diminution des particules LDL (une Apo B par particule), et un effet favorable sur l'évolution de la maladie coronarienne.

En contraste, les sujets qui expriment le phénotype A ne montrent pas, avec un régime abaissé en matières grasses, une diminution de l'Apo B, mais une diminution de la taille des
LDL (d'où une augmentation des «small LDLs»), une plus grande diminution des HDL2b, et presque deux fois l'augmentation du risque cardiovasculaire calculé selon le score de Framingham (figures 4 et 5).

Enfin, une sous-fraction de phénotype $A$, très sensible aux teneurs en glucides du régime, se transforme en phénotype $B$ en passant d'un régime à teneur lipidique élevée à un régime à teneur lipidique faible, et donc à un régime à teneur glucidique élevée, avec apparition de "small LDLs», de triglycerides élevés, d'HDL2b diminués.

Un régime excédentaire à taux glucidique élevé entraîne obligatoirement une synthèse de palmitique endogène, suivie souvent d'une synthèse d'oléique endogène particulièrement dangeureux en excès [47].

Les conséquences de cette dérive vers des régimes à teneur lipidique faible, à teneur glucidique élevée sont impressionnantes.

À l'âge pédiatrique, le phénotype $B$ dangereux représente 5 à $10 \%$ des sujets.

À l'âge adulte, pour $\mathrm{R}$ Krauss, le régime « Low Fats - High Carbohydrates » serait responsable de $36 \%$ de phénotypes $B$ supplémentaires [49].

Une question fondamentale se pose: pour améliorer $10 \%$ de la population, doit-on suggérer sur le plan national un régime dangereux pour $36 \%$ ?

\section{Le temps des synergies}

Sitôt découverte la myristoylation cotranscriptionnelle des peptides, et des protéines [50], sitôt connue la description des nouvelles structures physicochimiques (figure 2) [51] qu'elle engendrait, il apparaissait évident que ces modifications pouvaient entraîner des effets divers sur des protéines fonctionnelles, membranaires, sur des récepteurs. Ce tableau fut alors enrichi par la découverte de plus de cent protéines myristoylées. L'idée d'effets différents, compétitifs, permettant des régulations homéostasiques, LA versus myristique en sn-2, en particulier dans le système du Reverse Cholesterol Transport, semblait une hypothèse à vérifier.

Au moment même où Spady DK et al. [52] montraient que les acides gras polyinsaturés « up-régulaient » à hautes doses le récepteur SR B1 hépatique chez le hamster, tout en faisant baisser le taux de HDL circulants, nous avons pu montrer avec C. Loison [53] qu'à doses physiologiques, de 1,2 à 2,4\% de l'ET, le myristique en sn-2 « down-régulait » ce même récepteur également chez le hamster $(r: 0,75$, $p<0,0001)$ tout en augmentant le taux $d^{\prime} H D L$ circulants, le taux d'esters de cholestérol intrahépatique, sans que le récepteur LDL soit modifié et sans que la $3 \mathrm{HMGCOA}$ soit modulée. 


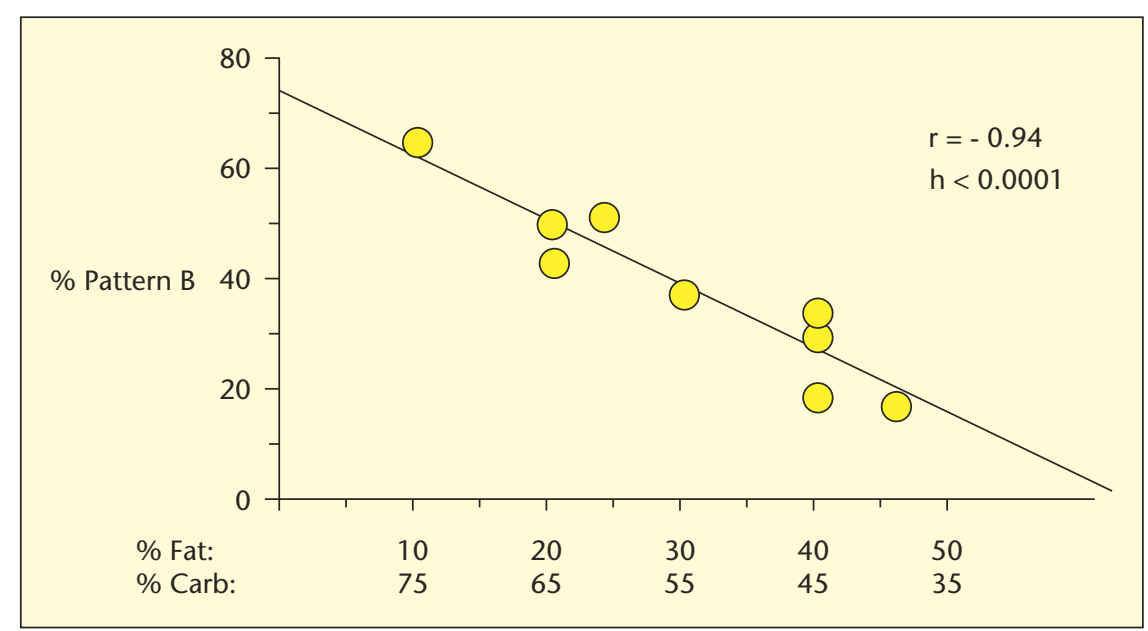

Figure 4. Prévalence de la sous-classe de LDL définie comme Pattern B en fonction du contenu en lipides et en glucides totaux du régime.

Ces données sont dérivées de cinq études regroupant un total de 596 hommes, en bon état de santé, non obèses, normolipidemiques. Les points figurant les données démontrent l'existence d'une corrélation :- \% pattern $B=-1.16$ (\% dietary fat $)+74(r=-94, p<0.0001)$ (d'après [49]).

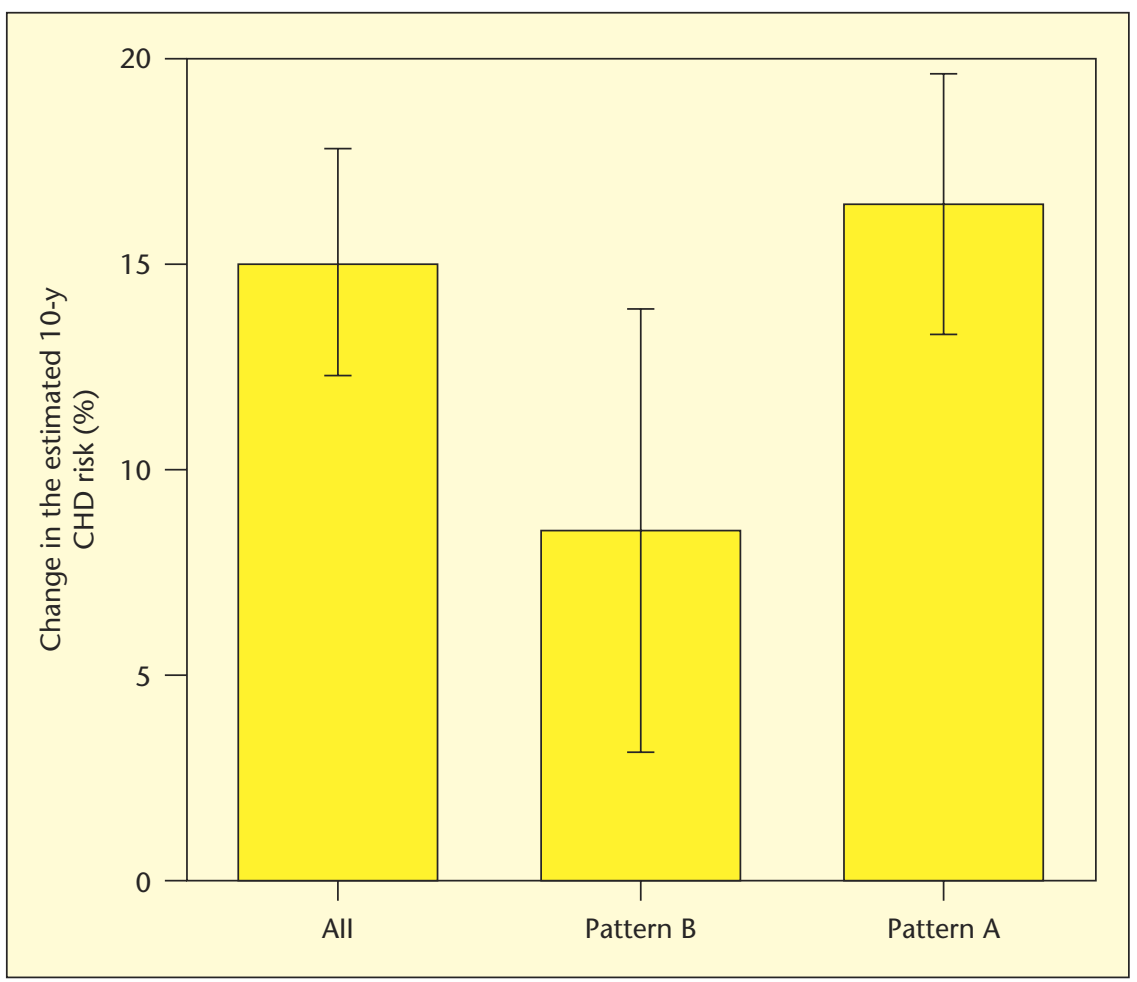

Figure 5. Moyenne (+/-SD) des pourcentages d'augmentation de risque de maladie coronaire cardiaque estimés à 10 ans, quand 105 hommes en bon état de santé,caractérisés par leur Pattern de sous-classe LDL, abandonnent un régime amenant $45 \%$ de l'énergie sous forme de lipides pour un régime amenant $24 \%$ d'énergie sous forme de lipides.

L'augmentation des projections de risque était significative pour la totalité de l'échantillon, et chez les hommes avec un Pattern A des LDL $(p<0,001)$ au départ. (D'après Williams PT, Krauss RM. Low Fat diets, lipoprotein subclasses, and heart disease Risk. Am / Clin Nutr $1999 ; 70$ : 949-50.).

Mais des données anciennes [54, 55] montraient, sans qu'elles fussent correctement interprétées le plus souvent, qu'une très bonne transformation de LA en DGLA (dihomogam- (myristique en sn-2), LA et ALA, pouvait-elle exister?

Nous avons pu montrer avec H. Dabadie [57, 58] que l'apport de myristique en sn- 2 au taux de 1,2 à 1,8\% de l'ET, au cours de deux brèves études de 5 semaines chez 25 moines une première fois, 19 moines une deuxième fois, augmentait le taux de DHA au niveau des esters de cholestérol de $61 \%(p<0,05)$ la première fois, de $32 \%(p<0,05)$ la deuxième fois. Un effet synergique myristique en $s n-2$, et ALA en $s n-2$, à doses physiologiques, serait-il la clé de cette augmentation naturelle de DHA ?

Dans le même temps V. Rioux, P. Legrand et al. montraient in vitro, sur des cultures d'hépatocytes, que le myristique augmentait l'activité delta- 6 désaturase de manière dose dépendante [59].

La teneur en AGHI ou AGPI d'un phospholipide membranaire, d'un ester de cholestérol, à un moment donné, est la résultante dans le temps d'un apport en acides gras parents, d'un équilibre entre tous les acides gras présents, d'une série de réactions chimiques sélectives, d'une régulation endocrino-métabolique, de l'équilibre entre une régulation anticipative et une régulation de rétrocontrôle, éventuellement d'une suppléance endogène [11] ou d'une redistribution systémique [12]. La notion de Reserve Drug appliquée à ces teneurs en $\mathrm{AGHI}$ des phospholipides est sans doute trop réductrice.

Cette étude chez les moines fut alors reprise dans une autre population de 27 moines, durant une durée plus longue, supérieure à trois mois, de façon à coïncider avec un renouvellement suffisant de la population des érythrocytes. C. Motta [60] put ainsi analyser la fluidité des membranes érythrocytaires en RPE chez ces 27 moines. L'amélioration obtenue a été spectaculaire et très significative. C'est la première fois qu'un tel résultat est obtenu. On est en présence d'une courbe en $U$, les meilleurs résultats sont obtenus avec $0,9 \%$ de I'ET sous forme d'alphalinolénique majoritairement en sn-2 (colza), et 1,2\% de l'ET sous forme de myristique en sn-2 (huile de beurre fractionnée).

$\mathrm{N}$. Combes et $\mathrm{C}$. Vaysse [61] ont pu étudier I'activité de la LCAT, par la méthode de Glomset chez ces mêmes sujets : " Pour des apports en ALA en sn-2 croissants (de $0,8 \mathrm{~g} / \mathrm{j}$ à $2,1 \mathrm{~g} / \mathrm{j}$ ), I'activité LCAT augmente en moyenne de $83 \%$. Pour des apports en myristique en sn-2 croissants $(2,9 \mathrm{~g} / \mathrm{j}$ à $4,2 \mathrm{~g} / \mathrm{j})$, I'activité LCAT augmente en moyenne de $38 \%$. Pour des apports en myristique de $2,9 \mathrm{~g} / \mathrm{j}$ contre $4,2 \mathrm{~g} / \mathrm{j}$, et ALA de $0,8 \mathrm{~g} / \mathrm{j}$ contre $2,1 \mathrm{~g} / \mathrm{j}$, croissants, I'activité LCAT augmente en moyenne de $152 \%$ ». Ici encore, une activité synergique est montrée. 
En matière de physiologie, les mots compétition, équilibre et synergie, doivent définitivement enterrer les mots opposition-exclusion (figure 6).

\section{Conclusion}

Durant près de vingt ans, «marketing de la science » et « discipline de la science » ont été confondus, faisant fi de toutes les «dissociations cognitives " selon l'expression de WEM Lands, de nombre d'incohérences. L'industrie pharmaceutique commence à en payer le prix. On pourrait dire qu'avec les farines animales introduites dans la phase d'immaturité digestive du jeune veau, le monde de l'élevage a également payé un certain prix.

Lors de la conférence de la Maison Blanche sur I'alimentation, la nutrition et la santé en 1969, « face à la clameur » sur la «malnutrition en Amérique " et au cours des auditions du Comité du Sénat sur la nutrition et les besoins humains (Rapport G. McGovern, January 1977 : 79-283 O), quatre forces déterminantes avaient été clairement identifiées. Elles ont dominé la fin du XXe siècle. On peut les regrouper sur deux axes:

- " désir de répondre à la demande de marché » (ou conquête d'un marché) face au " droit de connaître du consumérisme » (communication);

- « désir de plaire aux acheteurs... et aux électeurs » (Publicité) face au « désir de répondre à la force la plus déterminante de la bureaucratie fédérale ».

À l'épicentre, au point fluctuant d'équilibre, écartelé s'il n'y prend garde, se trouve en principe le scientifique.

Une éthique de l'information biologique était déjà réclamée, tout en signalant le danger de la laisser sous l'entier contrôle « de la force la plus déterminante de la bureaucratie fédérale ».

Trente ans ont passé, un bilan peut être fait. ॥ est évident que le monde de la recherche de la connaissance devra, pour être efficace, collaborer sans compromis avec ces quatre forces, mais sans cesser de lutter pour son indépendance, en restant très vigilant face aux dérives qu'elles peuvent engendrer. C'est la seule façon d'éviter les erreurs du XXe siècle.

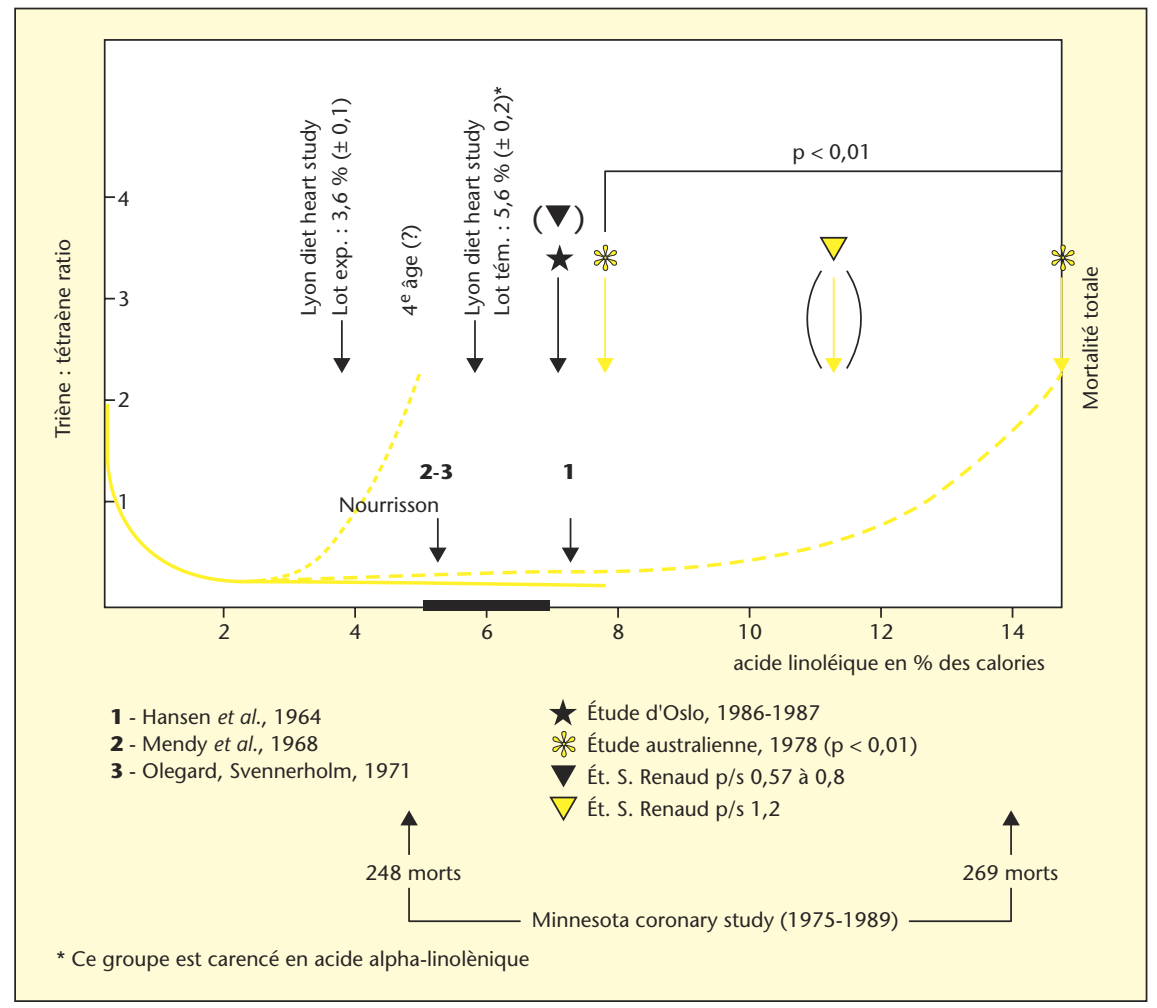

Figure 6. Adéquation de l'apport en linoléique aux besoins chez l'homme. Courbe en U.

La courbe de gauche, trait continu, a été calculée chez le rat par Holman. À partir de quelques points analysés chez I'homme, elle a été admise sans modifications pour I'homme, ouvrant la voie à des supplémentations en C18:2n-6 sans limite et sans réserve. Cela a été contredit par les travaux de Mendy, Olegard et Svennerholm. La courbe de droite est une courbe construite, confortée par l'étude d'Oslo, l'étude australienne, la Minnesota coronary study, les premières études de Renaud. La courbe centrale est déduite des travaux en gérontologie de Darcet, Driss (voir figure 2), confortée par les résultats de la Lyon Diet Heart Study. Le lot témoin de la Lyon Diet Heart Study était carencé en ALA 0,27\% Énergie (seuil de carence 0,4 et LA/ALA = 20).
Le temps des oppositions, des exclusions, doit laisser la place au temps des compétitions, de la recherche des équilibres et des déséquilibres, de la recherche des synergies.

\section{RÉFÉRENCES}

1. MENDY F. L'homme en cage, plaidoyer pour un nouvel évolutionnisme. Prospective et Santé 1977-1978 ; 4 : 63-84.

2. MENDY F. La Nutrition, une nouvelle Alchimie? Prospective et Santé $1983 ; 25: 134-42$.

3. FITZCERALD GA. Coxibs and Cardiovascular Disease. N Engl / Med 2004 ; 351(17) : 1709. 12.

4. BOURRE JM, DUMONT O, DURAND G. Doseeffect of dietary oleic acid : oleic acid is conditionnally essential for some organs. Reprod Nutr Dev 2004 ; 44(4) : 371-80.

5. BLANKENHORN DH, JOHNSON RL, MACK W], EL ZEIN HA, VAILAS LI. The influence of diet on the appearance of new lesions in Human Coronary Arteries. JAMA $1990 ; 263$ : 1646-52.

6. MIYASAKI M, CHIMAN W, NTAMBI JM. Targeted Disruption of Stearoyl-CoA Desaturase Gene in mice causes atrophy of Sebaceous and Meibomian Glands and depletion of Wax Esters in the Eyelids. / Nutr $2001 ; 131: 2260-8$.

7. HENDRICKS, et al. Safety of long-term consumption of plant sterols-esters enriched spreads. Eur / Clin Nutr 2003 ; 57 : 669-81.

8. HOLICK MF. Sunlight and vitaminD for bone health and prevention of autoimmune diseases, cancers, and cardiovascular disease. Am / Clin Nutr 2004; 80(suppl.): 1678S1688 S.

9. HOLMAN RT, JOHNSON SB, HATCH F. A case of human linolenic acid deficeincy involving neurological abnormalities. Am / Clin Nutr $1982 ; 35: 617-23$.

10. ELLEN G, ELGERSMA A, NIZO FOOD RESEARCH, KRAMER JKG, CRUZ-HERNANDEZ, OR-RASHID M, DUGAN MER. Agri-Food Canada Re $=$ Nomenclature of Trans-Fatty acids Lipids 2004 ; 7(39) : 693-6.

11. MENDY F, HIRTZI, BERRET R, RIO B, ROSSIER A. Etude de la composition en acides gras polyinsaturés des lipides sériques de nourrissons soumis à des régimes différents. Annales de la Nutrition et de l'Alimentation $1968 ;$ 5(22) : 267-85.

12. KULMACZ R], SIVARAJAN M, LANDS EM. Measurement of the incorporation of Orally administered arachidonic acid into tissue lipids. Lipids $1986 ; 1(21): 21-5$.

13. OLEGARD R, SVENNERHOLM L. Effects of diet on fatty acid composition of plasma and red cell phosphoglycerides in three-month-old infants. Acta Paed Scand 1971 ; 60 : 505-51.

14. HOLMAN RT. Essential Fatty Acid Deficiency in Humans. In : Galli C, Jacini G, eds. A Dietary Lipids and Post-Natal Development. New York: Pecile Raven Press Publishers, 1973 : 127-43. 
15. LASSERRE M, MENDY F, SPIELMANN D, JACOTOT B. Effects of different dietary intake of essential fatty acids on C20:3w6 and C20 :4w6 serum levels in Human Adults. Lipids $1985 ; 20: 227-33$.

16. DE LORGERIL M, RENAUD S, MAMELLE N, et al. Mediterranean alpha-linolenic acid-rich diet in secondary prevention of coronary heart disease. The Lancet $1994 ; 8911$ (343) : 1454-9.

17. TWISK J, GILLIAN-DANIEL DL, TEBONA. The role of the LDL receptor in Apolipoprotein B secretion. / Clin Invest $2000 ; 105$ : 521-32.

18. BEZARD J, CLOUET P. Biodisponibilité de I'acide alpha-linolénique. OCL 1997; 3(4): 191-6.

19. JONAS A. Mini-Review : Synthetic substrates of LCAT. J Lipid Res $1986 ; 27$ : 689-98.

20. EMKEN EA, ADLOF RO, GULLEY RM. Dietary linoleic acid influences desaturation and acylation of deuterium-labeled linoleic and linolenic acids in young adult males. B BA $1994 ; 1213$ : 277-88.

21. EMKEN EA, ADLOF RO, DUVAL SM, SHANE JM, ALKER PM, BECKER C. Effect of triacylglycerol structure on absorption and metabolism of isotope-labeled Palmitic and Linoleic acids by humans. Lipids $2004 ; 1(39): 1-9$.

22. BABIN F, RODRIGUEZ A, SARDA P, VANDEPUTTE $B$, MENDY F, DESCOMPS B. Alpha-linolenic acid in cholesterol esters : a marker of alphalinolenic acid intake in newborns. Eur / of Clin Nutr $2000 ; 54: 840-3$.

23. HU FB. Book Reviews « Prevention of Coronary Heart Disease ». Daan Kromhout, et al., eds. Diet, Lifestyle and Risk Factors in the Seven Countries Studies. Norwell, MA : Kluwer Academic Publishers, 2002 ; Am / Clin Nutr 2004, $79,168$.

24. KRIS-ETHERTON MP, HECKER KD, BINKOWSKI AE. Polyunsaturated Fatty Acids and Cardiovascular Health. Nutr Rev 2004 ; 11(62) : 414-26.

25. BRITISH MEDICAL RESEARCH COUNCIL. Controlled trial of soya-bean oil in myocardial infarction. Lancet $1968 ; 2: 693-9$.

26. HU FB, STAMPFER MJ, W WC. Dietary Saturated fatty acids in relation to the risk of CHD. Am I Clin Nutr $1999 ; 70$ : 1001-8.

27. LANDS WEM. Inform $2002 ; 13: 346$.

28. PERNOW B. Speech for the022Nobel prize for Physiology or Medecine 1982 ». In : Progress in Lipid Research. Pergamon Journals Ltd, 1982 : $19-20 ; 25$.

29. TOWLER DA, GORDON IJ, ADAMS SP, GLAZER L. The biology and enzymology of eukaryotic protein acylation. Annu Rev Biochem $1988 ; 57$ : 69-99.

30. JOHNSON DR, BHATNAGAR RS, KNOLL LI, GORDON JI. Genetic and Biochemical studies of protein-N-myristoylation. Annu Rev Biochem $1994: 63$.

31. CASEY PJ. Protein lipidation in cell signaling. Science $1995 ; 268: 221-5$.
32. MCILHINNEY RAJ. The fats of life : the importance and function of protein Acylation. Trends Biochem Sci $1990 ; 15$ : 387-91.

33. KLETT EL, PATEL $S$. Genetic defenses against noncholesterol sterols. Current Opinion in Lipid 2003 ; 4(14) : 341-6.

34. LANDS WEM. Functional foods in primary prevention or nutraceuticals in secundary prevention. Cur Topics in Nutrac Res 2003 ; 2(1) : 11320

35. LANDS WEM LE, TELLIER PR, ROME LH, VANDERHOEK JY. Inhibition of Prostaglandin Biosynthesis. Advances in Bioscience 1973; 9 : 15-27.

36. HAMBERG M, SVENSON J, SAMUELSON B. Thromboxanes: a new group of biologically active compounds derived from prostaglandin endoperoxides. Proceedings of the National Academy of Science USA $1975 ; 72: 2994-8$.

37. MONCADA S, GRYGLEWSKI R, BUNTING S, VANE J. An enzyme isolated from arteries transforms prostaglandin endoperoxides to an unstable substance that inhibits platelet aggregation. Nature 1976 ; 263(5579) : 663-5.

38. MCADAM BF, CATELLA-LAWSON F, MARDINI IA, KAPOOR S, LAWSON JA, FITZGERALD GA. Systemic biosynthesis of prostacyclin by cyclooxygenase-2 (COX2) : the human pharmacology of a selective inhibitor of COX-2. Proc Natl Acad Sci USA 1999 ; 96 : 272-7.

39. CITÉ PAR BEDFORD KEITH. New York Times 14 novembre 2004.

40. VANE JR. Comment of Role of Prostacyclin in the Cardiovascular Response to Thromboxane A2. Cheng Y, Austin SC, Rocca B, Koller BH, Goffman TH, Grosser T, Lawson JA, Fitzgerald GA. Science 2002 (296) : 539-541; « Back to an aspirin a day? » (296) : 474-5.

41. CURTIS C, HUGHES CE, FLANNERY CR, LITTLE CB, HARWOOD IL, CATERSON B. n-3 Fatty Acids Specifically Modulate Catabolic Factors Involved in Articular Cartilage Degradation. JBC $2000 ; 275(2): 721-4$

42. LEE JY, PLAKIDAS A, LEE WH, et al. Differential modulation of Toll-like receptors by fatty acids : Preferential inhibition by $n-3$ polyunsturated fatty acids. J Lipid Res 2003 ; 44 : 479-86.

43. MARCKMAN P. Fishing for Heart Protection. Am / Clin Nutr $2003 ; 78: 1-2$.

44. ERKKILA AT, LEHTO S, PYORALA K, UUSITUPA MJJ. n-3 fatty acids and 5-Y Risks of death and cardiovascular disease events in patients with coronary artery disease. Am J Clin Nutr 2003 ; $78: 65-71$.

45. JÜNI P, NARTEY L, REICHENBACH S, STERCHIR, DIEPPE PA, EGGER M. Risk of cardiovascular events and rofecoxib: cumulative metaanalysis. Lancet $2004 ; 364(9450): 2021-9$.

46. DIXON LB, ERNST ND. Choose a Diet That is Low in Saturated Fat and Cholesterol and Moderate in Total Fat: Subtle Changes to a Familar Message Diet. / Nutr 2001 ; 131 : 510S5265 .
47. RUDEL LL, PARKS IS, HEDRICK CC, THOMASM, WILLIFORD K. Lipoprotein and cholesterol metabolism in diet-induced coronary artery atherosclerosis in primates. Role of cholesterol and Fatty acids. Prog Lipi Res 1998 ; 37(6) : 353-70.

48. KRAUSS MR. Atherogenic lipoprotein phenotype and diet-gene interactions. / Nutr 2001 ; 131 : 340S-343S.

49. KRAUSS MR. dietary and genetic effects on low-density lipoprotein heterogeneity. Annu Rev Nutr 2001 ; 21 : 283-95.

50. BOUTIN J. Myristoylation. Cell Signal 1997 ; $91: 15-35$.

51. MCLAUGHLIN S, ADEREM A. The myristoylelectrostatic switch : a Modulator of reversible protein-membrane interaction. Trends Biochem Sci $1995 ; 20$ : 273-6.

52. SPADY DK, KEARNEY DM, HOBBS HH. Polyunsaturated fatty acids up- regulate hepatic scavenger receptor B1 (SR-B1) expression and HDL cholesteryl uptake in the hamster. / Lipid Res $1999 ; 40$ : 1384-94.

53. LOISON C, MENDY F, SEROUGNE C, LUTTON C. Dietary myristic acid modifies the HDLcholesterol concentration and liver scavenger receptor B1 expression in the hamster. Br J Nutr 2002 ; 87 : 199-210.

54. MOILANEN T, RÄSÄNEN L, VIKARI ], et al. Fatty acid composition of serum cholesteryl esters in 3- to 18-year-old Finnish children an dits relation to diet. Am / Clin Nutr 1985 ; 42 : 708-13.

55. CAMBIEN F, WARNET JM, VERNIER V, et al. An epidemiologic appraisal of the Associations between the fatty acids esterifying serum cholesterol and some Cardiovascular risk factors in middle-aged man. Am / of Epidemiology 1988 ; 127(1) : 75-86.

56. CRASTES DE PAULET A, BABIN F, BILLEAUD C, BOUGLE D, SARDA P, MENDY F. Effets biologiques, chez le prématuré, d'une supplémentation des Formules lactées en acide alphalinolénique: une étude multicentrique. Bull Acad Natle Méd 1994 ; 178(2) : 267-78.

57. DABADIE H, PEUCHANT E, BERNARD M, ET AL. Effects of three increasing intakes of myristic acid $(0.6,1.2$, and $1.8 \%$ of total calories), on lipidic parameters in a collectivity of monks. Abstracts 92nd AOCS Meeting 2001, 555.

58. DABADIE $\mathrm{H}$, PEUCHANT E, BERNARD M, MENDY F. Physiological intakes of Myristic acid from milk improve lipid profile. Lipid Technology $2004 ; 7(16): 149-52$.

59. JAN S, GUILLOU H, D'ANDREA S, et al. Myristic acid increases delta- 6 desaturase activity in cultured hepatocytes. Reprod Nutr Dev 2004 ; 44 : 131-40.

60. MOTTA C, DABADIE H, MENDY F, et al. 2005 ; (à paraître).

61. VAYSSE C, COMBES N, DABADIE H, et al. 2005 ; (à paraître). 